\title{
Zamanlararası Bütçe Kısıtı ve Türkiye'de Bütçe Açıklarının Sürdürülebilirliği
}

\section{The Intertemporal Budget Constraint and the Sustainability of Budget Deficits In Turkey}

\section{Arş. Grv. Süleyman Kasal ${ }^{1}$}

Başvuru Tarihi: 07.10.2019

Kabul Tarihi: 30.12.2019

Öz

Türkiye'de bütçe açıklarının sürdürülebilirliği özellikle son yıllarda dikkat çekici bir konu haline gelmiştir. Bütçenin ekonomiyi ciddi bir şekilde etkilediği düşünüldüğünde bütçe açıklarının sürdürülebilirliğinin analiz edilmesi bu kapsamda önemlidir. Çalışmanın kapsamı da bu fikir çerçevesinde oluşturulmuş ve Türkiye'de bütçe açıklarının sürdürülebilirliği zamanlararası bütçe kısıtı yaklaşımına dayalı olarak 2000: Ç1- 2018: Ç4 arası dönem için incelenmiştir. Çalışmada literatüre uygun bir şekilde merkezi yönetim reel gelirleri/GSYH ve merkezi yönetim reel harcamaları/GSYH değişkenleri kullanılmıştır. Bütçe açıklarının sürdürülebilir olup olmadı̆̆ Gregory ve Hansen (1996) tek yapısal kırılmalı eşbütünleşme testi aracılığıyla incelenmiştir. Uzun dönemli eşbütünleşme katsayısı FMOLS, DOLS, CCR ve IM-OLS yöntemleriyle tahmin edilmiştir. Analiz sonuçları Türkiye'de bütçe açıklarının zayıf formda sürdürülebilir olduğunu ortaya koymaktadır. Dolayısıyla analiz sonuçları Türkiye'de uygulanan mevcut bütçe politikalarında değişikliğe gidilmesi gerektiğine işaret etmektedir.

Anahtar Kelimeler: Bütçe Açı̆̆ı, Sürdürülebilirlik, Maliye Politikası, Eşbütünleşme Yöntemi

\begin{abstract}
The sustainability of budget deficits has especially become a questionable in recent years in Turkey. Considering that the budget has a serious impact on economic fundamentals, it is important to analyze the sustainability of budget deficits. The scope of the study has created in the frame of this idea and the sustainability of budget deficits has examined based on intertemporal budget constraint in the period between 2000: Q1 - 2018: Q4. In this study, central government real revenues/GDP, central government real expenditure/GDP variables are used in accordance with literature. It is examined whether the budget deficits are sustainable through the Gregory and Hansen (1996) structural cointegration test with one break. Long-run cointegration coefficient is estimated by FMOLS, DOLS, CCR and IM-OLS methods. Analysis results reveal that the budget deficit is sustainable in weak form in Turkey. Thus, analysis results indicate that it has need to change in the current budget policies implementing in Turkey.
\end{abstract}

Keywords: Budget Deficit, Sustainability, Fiscal Policy, Cointegration Method

\footnotetext{
${ }^{1}$ Anadolu Üniversitesi, İIBF Maliye Bölümü, skasal@anadolu.edu.tr, ORCID: 0000-0001-8409-1090
} 


\section{Giriş}

1990’lı yıllarda artan bütçe açıkları Türkiye'de uygulanan maliye politikalarının üzerinde düşünülmesi gerektiğini ortaya koymuştur. Mevcut politikalarda ısrar edilmesi 2000'li yılların başında Türkiye'nin çok ciddi bir ekonomik kriz yaşamasına neden olmuştur. Sonrasında ise yeni kamu mali yönetimi anlayışıla birlikte yeni bir aşamaya geçilmiştir. Temelde bütçe açıklarının azaltılmasına yönelik politikalar 2000'li yıllara damga vurmuştur. Nitekim 1990’lı yılların mevcut popülist bütçe politikaları ortadan kalkmış ve kamu mali disiplini üzerine kurulu bir anlayış maliye politikalarına hakim olmuştur. Hakim anlayış sonucu yaratılan kamu maliyesi Türkiye'de bütçe açıklarını azaltmıştır.

Son yıllarda ise Türkiye'nin karşı karşıya olduğu temel problemler yeniden bütçe açığını arttırıcı etkiler yaratmıştır. Nitekim maliye politikasının kullanımı açısından Türkiye’nin bir mali alanı olmasına rağmen, bütçe açıklarının olumsuz makroekonomik etkilerinin olabileceği dile getirilmeye başlanmış ve bütçe açığını arttırıcı yöndeki mevcut politikalar riskli görülmeye başlanmıştır. Dolayısıyla çalışmanın konusunu da Türkiye'de 2000: Ç1-2018: Ç4 arası dönemde bütçe açıklarının sürdürülebilirliği oluşturmaktadır.

Ampirik analizler çerçevesinde bütçe açıklarının sürdürülebilirliği literatürde birçok farklı bakış açısı ve yöntem çerçevesinde test edilmiştir. Genel olarak sürdürülebilirliğin analizi birim kök testleri, eşbütünleşme testleri ve model temelli sürdürülebilirlik yaklaşımları çerçevesinde gelişmiş ve gelişmeye de devam etmektedir. Bu çalışmada bütçe açıklarının sürdürülebilirliği analizi Quintos (1995)'in öne sürdürdügü sürdürülebilirlik kriterleri esas alınarak analiz edilecektir. Bu çalışmalar çerçevesinde 2000: Ç1-2018: Ç4 döneminde bütçe açıklarının sürdürülebilirliğini test etmek üzere Ziwot-Andrews (1992) tek yapısal kırılmalı birim kök testi, Gregory ve Hansen (1996) tek yapısal kırılmalı eşbütünleşme testi ve uzun dönem eşbütünleşme katsayılarını tahmin etmek üzere de Phillips ve Hansen (1990) tarafından geliştirilen FMOLS (Fully Modified Ordinary Least Squares), Park (1992) tarafından geliştirilen CCR (Canonical Cointegrating Regression), Stock ve Watson (1993) tarafından geliştirilen DOLS (Dynamic Ordinary Least Squares) ve Vogelsang ve Wagner (2014) tarafından geliştirilen IM-OLS (Integrated Modified Ordinary Least Squares) tahmincileri kullanılacaktır.

Makale şu şekilde organize edilmiştir: İlk olarak bütçe açıklarının sürdürülebilirliği konusu teorik olarak açıklanacak, sonrasında konuyla ilgili ampirik literatüre yer verilecektir. Üçüncü olarak ise çalışmada kullanılan model, veri ve yöntem açıklanacaktır. Dördüncü bölümde tahmin sonuçlarına yer verilecek ve daha sonrasında makale sonuç bölümüyle tamamlanacaktır.

\section{Bütçe Açıklarının Sürdürülebilirliği}

İktisadi yaklaşımların odak noktalarından birisi de bütçe açıkları olmuştur. Klasik iktisadi yaklaşım, Neo-Klasik iktisadi yaklaşım, Keynesyen iktisadi yaklaşım, Monetarist iktisadi yaklaşım, Kamu Tercihi Teorisi ve Post Keynesyen iktisadi yaklaşım bütçe açıklarıyla ilgili çok çeşitli fikirler öne sürmüşlerdir. Klasik iktisadi yaklaşımın "devleti zorunlu bir fena olarak görmesi” sonucu ortaya koyduğu fikir bütçenin hem küçük hem de denk olmasıydı (Şen vd., 
2007, s. 38). Neo-Klasik iktisadi yaklaşımda ise önemli olanın geçici bütçe açıkları değil, sürekli bütçe açıkları olduğu savunulmuştur. Çünkü bir ekonomide bireylerin rasyonel ve ileri görüşlü olduğu varsayımı altında sürekli bütçe açıkları sermaye birikimini önemli ölçüde azaltacaktır (Ataç, 2013, s. 227). Ancak Büyük Buhran'ın 1929 yılında iktisat politikalarına hakim olan bu anlayışı yerle bir etmesi Keynesyen iktisadi yaklaşımı öne çıkarmıştır. Keynesyen iktisadi yaklaşımın varsayımları gereğince devletin bütçeyi aktif bir şekilde kullanabileceği öne sürülmüş ve uygulanan politikaların olumlu makroekonomik sonuçlara neden olması dönemin egemen iktisadi anlayışı olmasını sağlamıştır. Ancak yüksek bütçe açıklarının ortaya çıkması Keynesyen iktisadi yaklaşımın sorgulanmasına neden olmuş ve alternatif iktisadi yaklaşımların ortaya çıkmasına neden olmuştur. Bu eleştirilerden birisi Buchanan'ın öncülük ettiği Kamu Tercihi Teorisi' dir. Buchanan, Keynesyen iktisadi yaklaşımın temel varsayımının yanlış olduğu ve politika yapıcıların da insan olduğunu söyleyerek, onların toplumun çıkarlarına göre değil kendi çıkarlarına göre hareket ettiğini öne sürmüştür. Dolayısıyla bu aktörlerin daha büyük hükümet, büyük bütçe ve bütçe açıklarına yönelik sapma yaratacağını ve bu açıkların çok olumsuz etkileri olacağını savunmuştur (Pressman, 2001, s. 105-106). Monetarist iktisadi yaklaşım bütçe politikası uygulamalarının toplam talep üzerindeki etkilerinin tesadüfi veya geçici nitelikte olduğunu ve bu nedenle maliye politikası araçlarının talebi etkilemedeki ve ekonomik istikrarı sağlamadaki rolünün sınırlı olduğunu ileri sürmektedir (Egeli ve Özen, 2017, s. 97). Bu nedenle de bütçenin denk olması gerekmektedir. Post-Keynesyen iktisadi yaklaşımda Keynes’in görüşlerinden yola çıkarak, devleti belirsizliği azaltan bir kurum olarak görmektedir. Belirsizliğin azaltılmasıyla devletin güveni arttırabileceğini ve ekonomik performansı geliştirebileceğini öne sürmüşlerdir (Pressman, 2001, s. 111).

Kamu gelirlerinin kamu harcamalarından az olması sonucu ortaya çıkan bütçe açıları üzerinde düşünülmesi gereken önemli konulardan birisidir. Nitekim bir ülkede bütçe açılarının sürekli artışı makroekonomik açıdan mümkün değildir. Bunun temel nedenleri uygulanan politikalarda gizlidir. Çünkü bütçe açıkları uygulanan maliye politikalarının bir yansıması olarak ortaya çıkmaktadır. Genişletici maliye politikası uygulamasının sürekliliği ve ekonomi üzerinde beklenen olumlu etkiyi göstermemesi kamu gelir-gider dengesinin gelir aleyhine daha fazla bozulmasına neden olur. Kamu gelirlerinin istenilen seviyede gerçekleşmemesi ve kamu gelirleri açısından yeni politikaların uygulama alanının olmaması kamunun borçlanma yoluyla gelir aramasına yol açmaktadır. Bütçe açıkları ile borçlanma arasında doğrudan bir ilişki mevcuttur. Çünkü açı yönlü bütçe politikalarının kısa dönemde uygulama olanağı olsa bile, uzun dönemde borçlanmayı etkilediği bilinmektedir. Dolayısıyla borçluluğun artışı faiz ödemeleri nedeniyle bütçe üzerinde tekrar bir yük meydana getirmektedir.

Sürdürülebilirlik; bütçe politikası çerçevesinde hükümetlerin bugünkü ve gelecekteki harcama yükümlülüklerini karşılayacak şekilde finansmanlarını yönetme biçimi olarak da tanımlanabilmektedir (Özcan, 2011, s. 229). Ancak bütçe açıklarının sürekli artışı beklentiler kanalıyla da ekonomiyi olumsuz yönde etkilemektedir. Beklentilerin bozulduğu bir ekonomik ortamda da düşük risk primlerinin oluşması çok mümkün değildir. Yüksek risk primlerinin veya bir başka deyişle finansman maliyetlerindeki artışın kamunun ödeme gücü kabiliyetini de olumsuz etkileyeceği söylenebilir. Risk primlerinin artışı sabit sermaye yatırımlarının 
azalmasına sebebiyet verir. Ayrıca ülke faiz oranının yüksekliği ise ülkeye girecek sıcak para akışını hızlandırabilir. Bu paranın spekülatif yatırımlar sonucu aşırı borçlanmaya ve risk almaya neden olması finansal piyasalarda varlık balonlarının oluşmasına neden olabilmektedir (Ulusoy vd., 2015, s. 6). Bu durum ekonomiyi tümüyle kırılgan bir hale getirebilmektedir. Bu nedenle mevcut bütçe açıklarının sürekli artışı kamu borçlarını olumsuz bir şekilde etkileyerek borçların sürdürülebilirliği endişesini de gündeme getirebilir. Çünkü sürekli açık veren bir ekonomide, açıkların borçlanmayla finanse edilmesi, faiz ve borç yükünün hızlı artışına ve borçlanma politikasının çökmesine neden olacaktır (Özcan, 2011, s. 230). Bu nedenle bütçe açıklarının endişe yaratmaması ve sürdürülebilir olması açısından temelde bütçe politikalarının dikkatlice tasarlanması gerekir.

Bütçe açılarının sürdürülebilirliğinin analizi ekonomik göstergelerle ve ekonometrik yöntemlerle yapılabilmektedir. Ekonomik göstergelerle analiz Buiter (1985)'in öncülügünde, ekonometrik yöntemlerle analiz ise Hamilton ve Flavin (1986)'nın öncülügünde gelişmiştir (Şen vd. 2010, s. 105). Ekonometri temelindeki yaklaşımlardan birisi zamanlararası bütçe kısıtı yaklaşımıyken, diğeri de bugünkü değer kısıtı yaklaşımıdır. Zamanlararası bütçe kısıtı yaklaşımı temel olarak Hamilton ve Flavin'in 1986 yılında yapmış oldukları çalışmaya dayanmaktadır. Bu çalışmadan sonra yapılan çalışmalar ekonometrideki gelişmelerin ortaya çıkması ve yeni yaklaşımların geliştirilmesi yoluyla ülkeler düzeyinde uygulanmaktadır (Özcan, 2011, s. 234237). Hükümetin bir dönemlik bütçe sınırı şu şekilde yazılabilmektedir (Hakkio ve Rush (1991);

$$
G_{t}+\left(1+i_{t}\right) B_{t-1}=R_{t}+B_{t}
$$

Burada $G_{t}$ kamu harcamalarını, $R_{t}$ kamu gelirlerini, $i_{t}$ ise faiz oranını göstermektedir. Eşitlik (1) ileriki dönemler esas alınarak çözülürse, bu bir dönemlik bütçe kısıtı hükümetin zamanlararası bütçe kısıtını oluşturur ve şu şekilde gösterilir:

$$
B_{0}=\sum_{t=1}^{\infty} r_{t}\left(R_{t}-G_{t}\right)+\lim _{n \rightarrow \infty} r_{n} B_{n}
$$

Buradaki $\lim _{n \rightarrow \infty} r_{n} B_{n}$ terimi sıfıra eşit olursa, bütçe fazlalarının toplam borç stokuna eşit olduğunu ve hükümetin zamanlararası bütçe kısıtını sağladığı varsayılmaktadır. Nitekim eğer sıfıra eşit olmazsa hükümet, harcamalarının finansmanını sürekli borçla sağlayacak ve vadesi gelen borçlar yeni borçlanmayla finanse edilecektir. Hakkio ve Rush (1991) eşitlik (2)'yi test edilebilir bir forma dönüştürerek aşağıdaki eşitliği elde etmişledir:

$$
R_{t}=a+b G_{t}+\varepsilon_{t}
$$

Buradaki $R_{t}$ kamu gelirlerini, $G_{t}$ ise kamu harcamalarını temsil etmekte, $\varepsilon_{t}$ ise hata terimlerini göstermektedir. Yazarlar $R_{t}$ ve $G_{t}$ 'nin durağan olmadığ bir durumda eşbütünleşme ilişkisinin varlığını sürdürülebilirlik açısından gerekli bir koşul olarak görmüşlerdir. Burada bütçe açıklarının sürdürülebilir olup olmadığı kararını ise $b=1$ ile test etmişler, katsayının bire eşit olmasının sürdürülebilir bir bütçe açığını sağladığını ileri sürmüşlerdir. $b<1$ olduğu 
durumda ise hükümetlerin gelirlerinden çok harcadıklarını dolayısıla bütçe açıllarının sürdürülemez olduğunu savunmuşlardır. Quintos (1995) ise yapısal değişiklikleri de dikkate alarak yaptığı çalışmada bütçe açıklarının sürdürülebilirliği için güçlü ve zayıf koşullar belirlemiştir. Güçlü koşulu; Trehan ve Walsh (1988)'de öne sürüldüğü gibi, harcama ve gelirlerin eşbütünleşik olması yaklaşımına benzer bir şekilde tanımlamıştır. Zayıf koşul olarak ise; uzun dönemli dengenin daha yavaş bir şekilde gerçekleştiği ve borcun ekonomik büyüme oranını geçmediği sürece bütçe açıklarının hala sürdürülebilir olduğu ve bu nedenle eşbütünleşme ilişkisinin varlığının bütçe açıklarının sürdürülebilirliğgi için sadece yeterli olduğu bir süreç olarak açıklamıştır. Dolayısıyla $b<1$ olduğu durumun zayıf anlamda bir sürdürülebilirlik göstergesi olduğunu ileri sürmüştür. Ancak Quintos (1995)'in zayıf anlamda ele aldığı koşulun sağlanmış olsa bile bütçe açıklarının uzun dönemde hükümetin politikaları üzerinde ciddi etkileri olacağını belirtmiştir. Bu nedenle uygulanan maliye politikalarının gözden geçirilmesi gerekmektedir.

\section{Ampirik Literatür}

Bütçe açıklarının sürdürülebilir olup olmadığı hem uygulanacak maliye politikaları hem de bu politikaların yaratacağı etki açısından önemli bir soru işaretidir. Bu soru işaretinin giderilmesi için de literatürde çeşitli ülke ve dönemleri esas alan çalışmalar yapılmış ve yapılmaya devam etmektedir. Ancak bu çalışmalar bazı noktalarda birbirinden ayrılmaktadır. Hamilton ve Flavin (1986) ABD'de bütçe açılkarının 1962-1984 yılları arasında sürdürülebilir olup olmadığını analiz etmek için reel kamu borcunun ve reel bütçe açığının durağanlığını sınamışlar ve durağanlığın açıkların sürdürülebilir olduğunu gösteren bir sonuç olduğunu öne sürmüşlerdir. Her iki seriyi de durağan bulmuşlar, dolayısıyla zamanlararası bütçe kısıtının ihlal edilmediğini ortaya koymuşlardır. Ancak yazarların yaptıkları çalışmanın sonuçları hem ele alınan dönemin kısa oluşu (22 yll) hem de ekonometrik olarak birim kökün \%10 seviyesinde reddedilirken, \%5 seviyesinde reddedilemeyişi nedeniyle oldukça zayıf (fairly weak) bir sonuç olarak bulunmuştur. Hakkio ve Rush (1986) ABD için bütçe açıklarının sürdürülebilirliğini 1962-1986 dönemini çeyreklik olarak faiz dışı açık verisi üzerinden birim kök aracılığıyla incelemişler ve faiz dışı açığın durağan bulunmasıyla zamanlararası bütçe kısııııın sağlandığı sonucuna ulaşmışlardır. Trehan ve Walsh (1988) faiz ödemelerini dahil etmeyen bir bütçe açı̆̆ının durağanlığı üzerine yapılacak yorumun zamanlararası bütçe kısııını sağlamakta ne gerekli ne de yeterli bir koşul olduğunu öne sürmüşler ve faiz ödemelerinin de dahil edildiği geleneksel bütçe açığı üzerine yoğunlaşmışlardır. Ayrıca yazarlar zamanlararası bütçe kısıtının sağlanma koşulunu faiz dahil harcamaların, vergi ve senyoraj gelirleriyle eşbütünleşik olmasıyla açıklamışlardır. Yazarlar ABD için 1890-1986 dönemini incelemişler ve bütçe açılarının sürdürülebilir olduğu sonucuna ulaşmışlardır. Wilcox (1989) 1960-1984 dönemini ABD için analiz etmiş ve Hamilton ve Flavin (1986)'nın aksine politikaların sürdürülebilir olmadığ sonucuna ulaşmıştır. Trehan ve Walsh (1991) beklenen reel faiz oranının sabit olduğu varsayımı altında zamanlararası bütçe kısıtı için gerekli ve yeterli bir koşul türeterek borç stoku, faiz dışı açık ve bütçe açığı üzerine birim kök testi uygulamışlar, borç stoğu dışındaki serilerin durağan olduğunu ve bütçe açıklarının sürdürülebilir olduğu sonucuna ulaşmışlardır. Hakkio ve Rush (1991) ABD için 1950: Ç2-1988: Ç4 dönemini iki alt döneme ayırıp (sırasıyla 1964: Ç1-1988: Ç4 ve 1976: Ç3-1988: Ç4) reel kamu gelirleri ve reel kamu harcamalarının hem düzey 
değerlerini hem de nüfusa ve GSYH'ye oranını kullanarak eşbütünleşme analiziyle incelemişler, sonuç olarak kamu harcamalarının kamu gelirlerinden daha hızlı büyüdüğünü ve bütçe açıklarının sürdürülemez olduğunu bulmuşlardır. Quintos (1995) yapısal değişmeleri dikkate alarak bütçe açıklarının sürdürülebilir olup olmadığını ABD için 1947: Ç2-1992: Ç3 dönemi için hem kırılmasız model hem de kırılmalı model kullanarak FMOLS yöntemiyle incelemiştir. Tüm dönem için bütçe açığının güçlü anlamda olmasa da sürdürülebilir olduğunu, içsel olarak belirlediği kırılma tarihleriyle birlikte (sırasıyla 1975: Ç2 ve 1980: Ç4) oluşturduğu kırılmalı modelinin sonuçlarına göre ise kırılma tarihinden önceki dönemde bütçe açıklarının güçlü anlamda sürdürülebilir olduğunu ancak kırılma tarihinden sonraki dönemde ise bütçe açıklarının zayıf formda sürdürülebilir olduğunu ortaya koymuştur.

Türkiye ile ilgili çalışmalara gelindiğinde bütçe açıklarının sürdürülebilirliğinin birim kök ve eşbütünleşme testleriyle birlikte veya ayrı ayrı incelendiği görülmektedir. Özatay (1997) bütçe açıklarının sürdürülebilir olup olmadığını 1985: 5-1993: 12 dönemi için reel iç borç stokunun logaritmasına birim kök testi uygulayarak araştırmış ve serinin birim kök içerdiğini dolayısıyla 1993 öncesi sürdürülebilirliğin sağlanmadığı sonucuna ulaşmıştır. Kuştepeli ve Önel (2005) bütçe açıklarının sürdürülebilir olup olmadığını toplam kamu geliri ve faiz dahil toplam kamu harcaması verilerini kullanarak kırılmalı eşbütünleşme testiyle incelemişlerdir. Uzun dönem eşbütünleşme katsayılarını tahmin etmek için DOLS tahmincisi kullanmışlar ve elde ettikleri sonuca göre bütçe açıklarının zayıf formda sürdürülebilir olduğunu bulmuşlardır. Payne vd. (2008) 1968-2004 dönemini yapısal kırılmalı eşbütünleşme yöntemini kullanarak incelemiş ve bütçe açıklarının zayıf sürdürülebilir olduğu sonucuna ulaşmışlardır. Ayrıca yazarlar eşikli otoregresif modellerini (Threshold autoregressive (TAR)-momentum threshold autoregressive (MTAR)) kullanarak bu dönem için bütçe uyum sürecinin asimetrik olduğu hipotezini desteklemediği bulgusuna ulaşmışlardır. Göktaş (2008), 1987: 1-2007: 3 dönemini iki alt döneme ayırarak (sırasıyla 1987: 1-2003: 2 ve 2003: 3-2007: 3) için bütçe açıklarının sürdürülebilir olup olmadığını eşbütünleşme yöntemiyle araştırmış, tüm dönem ve alt dönemler için bütçe açığının zayıf formda sürdürülebilir olduğu sonucuna ulaşmıştır. Şen vd. (2010) 1975-2007 dönemi için mali sürdürülebilirliği test ettikleri çalışmanın ilk kısmında bütçe açıkları, borç stoku ve faiz ödemelerine birim kök testleri uygulamış, ikinci kısmında ise konsolide bütçe gelirleri ve faiz dahil konsolide bütçe harcamalarını eşbütünleşme yöntemleri kullanarak incelemişlerdir. İlk kısımda uyguladıkları birim kök testleri sonucunda serilerin durağan olmadığını bulmuşlar, ikinci kısımda ise eşbütünleşmeye dair bir kanıt bulamamışlar ve bu nedenle incelenen dönemde Türkiye'de mali sürdürülebilirliğin olmadığı sonucuna ulaşmışlardır. Altun (2017) bütçe açılarının sürdürülebilir olup olmadığını çeşitli birim kök testleri aracilğ̆ılla incelemiş ve Türkiye'de bütçe açıllarının durağan olduğu sonucuna ulaşmış ve bütçe açıklarının sürdürülebilir olduğu sonucuna varmıştır. Akkuş ve Durmaz (2019) ise bütçe açıklarının sürdürülebilirliğini 1930-2016 dönemini iki alt dönem ayırarak (sırasıyla 1930-1979 ve 1980-2016) saklı eşbütünleşme yaklaşımıyla incelemişler ve eşbütünleşme tahmincileriyle (FMOLS, DOLS, CCR) elde ettikleri sonuca göre Türkiye'de bütçe açılarının zayıf sürdürülebilir olduğu sonucuna ulaşmışlardır. 


\section{Model, Veri ve Yöntem}

Literatürde bütçe açıklarının sürdürülebilir olup olmadığı ekonometrik olarak birim kök ya da durağanlık testleri ve eşbütünleşme testleri ile analiz edilmektedir. Nitekim literatür kısmında da belirtildiği gibi birçok yazar bu testleri kullanarak incelemeye alınan ülke ve dönem için analizlerini gerçekleştirmiştir. Bu nedenle çalışmada Türkiye'de ele alınan dönem için bütçe açıklarının sürdürülebilirliği literatüre uyumlu bir şekilde değişkenler arasında eşbütünleşme ilişkisi araştırılarak analiz edilecektir. Ancak çalışmanın literatüre hem incelenen dönem açısından hem de metodoloji açısından katkısı olabileceği düşünülmektedir. Analize geçmeden önce değişkenlerin hangi düzeyde bütünleşik olduğunu öğrenmek için birim kök testi uygulanacaktır. Değişkenlerin birim kök içerdiği sonucuna ulaşılırsa iki değişken arasında eşbütünleşme ilişkisinin olabileceği ihtimaliyle eşbütünleşme ilişkisi araştırılacaktır. Daha sonra ise uzun dönem eşbütünleşme katsayı tahmincileriyle Eşitlik (4)'teki $b$ katsayısı tahmin edilecektir.

Çalışmada bütçe açıklarının sürdürülebilirliğini analiz etmek için tahmin edilecek model aşağıdaki gibidir:

$$
\text { rgelir }=\beta_{1}+\text { brharc }+\beta_{3} \text { trend }+\beta_{4} D U+\varepsilon_{t}
$$

Modelde rgelir; merkezi yönetimin reel gelirlerinin reel GSYH'ye oranını ifade ederken, rharc; merkezi yönetim reel harcamalarının reel GSYH'ye oranını ifade etmektedir. $D U$ yapısal kırılmayı ifade eden kukla değişkeni, $\varepsilon_{t}$ ise hata terimlerini göstermektedir. Modele ayrıca trend değişkeni eklenmiştir. Model tahmini sonucu Türkiye'de bütçe açıklarının sürdürülebilirliği konusundaki yorum $b$ katsayısına bakılarak yapılacaktır.

Çalışmada merkezi yönetim gelirleri ve faiz dahil harcama verileri kullanılmıştır. Değişkenlerin tamamı reel hale getirilmiş ve reel GSYH’ye oranlanmıştır. Verilerin tamamı çeyreklik kümülatif olarak TCMB-EVDS'den (Elektronik Veri Dağıtım Sistemi) elde edilmiştir. Tüm ekonometrik analizler Gauss 19 ve R Studio 3.6.1 kullanılarak yapılmıştır.

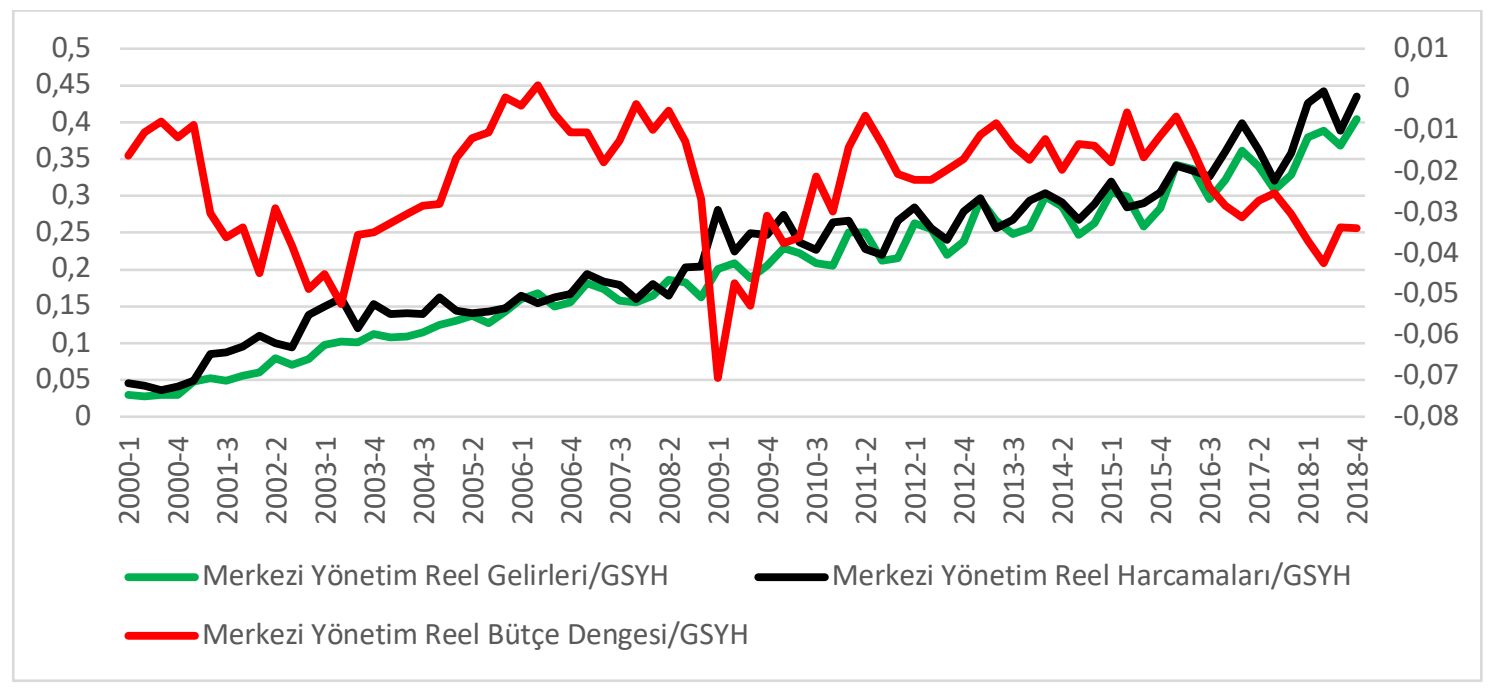

Şekil 1.rgelir ve rharc Değişkenlerine Ait Grafik ve Bütçe Dengesi, 2000: Ç1-2018: Ç4, (\%) 
Şekil 1'de merkezi yönetimin reel gelir ve harcamalarının reel GSYH içindeki payının arttığ görülmektedir. Ayrıca bilgi açısından merkezi yönetim reel bütçe dengesi de grafikte verilmiştir. Tablo 1'de ise analizde kullanılan $r$ gelir ve $\operatorname{rharc}$ değişkenlerine ait tanımlayıcı istatistikler yer almaktadir.

Tablo 1. Tanımlayıcı Ístatistikler

\begin{tabular}{|l|l|l|}
\hline & \multicolumn{1}{|c|}{ rgelir } & \multicolumn{1}{c|}{ rharc } \\
\hline Ortalama & 0.198281 & 0.220839 \\
\hline Medyan & 0.202741 & 0.225734 \\
\hline Maksimum & 0.404426 & 0.442199 \\
\hline Minimum & 0.027657 & 0.036082 \\
\hline Standart sapma & 0.098948 & 0.099526 \\
\hline
\end{tabular}

Çalışmada değişkenlerin hangi derecede bütünleşik olduğunu öğrenebilmek için öncelikle değişkenlere birim kök testi uygulanacaktır. Birim kök testi olarak kırılmalı birim kök testlerinden Ziwot ve Andrews (1992)'in tek kırılmalı ADF (Augmented Dickey-Fuller) testi kullanılacaktır. Sonrasında ise eşbütünleşme testi olarak Gregory ve Hansen (1996)'da geliştirilen yapısal kırılmalı eşbütünleşme testi uygulanacaktır. Bu testin kullanılmasının temel nedeni geleneksel eşbütünleşme yöntemlerinin önemli bir sınırının varlığıdır. Nitekim geleneksel eşbütünleşme yöntemleri yapısal kırılmaların olduğu bir durumda istikrarlı eşbütünleşme ilişkilerinin olmasına rağmen eşbütünleşme ilişkisinin varlığını reddetmeye eğilimlidirler (Mensah, 2014, s. 176). Gregory-Hansen (1996) ise yapısal kırılmanın varlığını dikkate alarak bir eşbütünleşme testi geliştirmiştir. Bu eşbütünleşme testi Ziwot ve Andrews (1992) birim kök testinin uzantısı olarak düşünülmektedir (Yılancı ve Özcan, 2010, s. 26). Test hata terimlerine dayalı olarak örneklem dönemi içerisinde bilinmeyen yapısal kırılmanın varlı̆̆ında geliştirilmiş bir eşbütünleşme testidir. Yazarlar sabit terimde ve/veya eğim parametresindeki değişimleri yansıtan bilinmeyen bir değişim noktası tanıtarak uzun dönemli eşbütünleşme ilişkisinin yeni uzun dönem ilişkisine doğru değiştiğini ileri sürmüşlerdir. Gregory ve Hansen (1996) da yapısal değişimin birçok form alabileceğini öne sürmüştür. Bunun üzerine yazarlar düzeyde değişim modeli $(C)$, trendli düzey değişim modeli $(C / T)$ ve rejim değişim modeli $(\mathrm{C} / \mathrm{S})$ olmak üzere 3 model geliştirmişlerdir. Model tahminleri sonucu test istiatistikleri hesaplanır. Hesaplanan test istatistikleri tablo kritik değerleriyle karşılaştırılarak değişkenler arasında eşbütünleşme olup olmadığına karar verilir. Eğer hesaplanan test istatistik değerleri tablo kritik değerlerinden büyük ise eşbütünleşmenin olmadığını gösteren $H_{0}$ hipotezi reddedilir ve değişkenler arasında tek yapısal kırılmayla birlikte eşbütünleşme ilişkisi vardır sonucuna ulaşılır (Kırca ve Topal, 2017, s. 104).

Uzun dönem eşbütünleşme katsayılarının tahmini için ise FMOLS, DOLS, CCR ve IM-OLS yöntemleri kullanılacaktır. Bu yöntemlerin tamamı sıkça kullanılan yöntemler olup birbirini destekler niteliktedir. Dolayısıyla tutarlılığı sağlamak adına bu dört yöntemin çalışmada kullanılması tercih edilmiştir. Tabi ki bu yöntemler birbirini destekler nitelikte olsa da uzun dönemli eşbütünleşme katsayılarının hesaplanması açısından farklı aşamalar içermektedir. $\mathrm{Bu}$ yöntemlerden FMOLS asimptotik sapmaları ortadan kaldırmak adına model tahmininde iki 
aşamalı bir yöntem kullanmaktadır. Bu yöntem hem verinin hem de parametrelerin dönüşümüne odaklanmaktadır (Adom vd. 2015, s. 31). CCR yöntemi ise eşbütünleşme modelindeki durağan içerikleri kullanarak hem bağıml hem de bağımsız değişkenleri dönüştürmekte, böylece otokorelasyon sorununu ortadan kaldırmaktadır (Han, 1996, s. 236). DOLS yönteminde ise katsayı tahmininde herhangi bir otokorelasyon sorununu asimptotik olarak ortadan kaldırmak için öncül ve gecikmeler kullanılmaktadır (Montavo, 1995, s. 231). Ayrıca DOLS tahmincileri içsellik probleminin varlığında bile sapmasız ve asimptotik olarak etkindir. IM-OLS yöntemi de FMOLS tahmincisi gibi iki adımlıdır. Ancak IM-OLS yönteminde bandwith, kernel veya gecikme uzunluğu gibi seçimlerden tamamen kaçınılmaktadır. IM-OLS tahmincisi regresyon modelinin genişletilmiş kısmi toplam dönüşümünün OLS tahminine dayanmaktadır. Ancak bu tahmin yöntemi yine de uzun dönem varyans parametresinin tahminini gerektirmektedir. Vogelsang ve Wagner (2014) de buna iki çözüm sunmaktadır. Birincisi, uzun dönem varyansın tutarlı bir tahmincisine dayanan standart asimptotik çıkarım, ikincisi ise sabit-b çıkarımına dayalıdır. Vogelsang ve Wagner (2014) simülasyon çalışmalarına dayalı olarak IM-OLS tahmincisini DOLS ve FMOLS tahmincileriyle karşılaştırmışlar ve IM-OLS tahmincisinin hem sapma hem de hataların ortalama kare kökü (RMSE) açısından iyi performans gösterdiğini ortaya koymuşlardır. Ancak otokorelasyon ve içsellik sorunu olduğu durumda DOLS ve FMOLS tahmincilerinin sıfır hipotezini aşırı red sorunu yaşadıkları, bu durumda ise Quartlett-Spectral kernel tahmincili IM-OLS tahmincisinin tercih edilmesinin bu sorunu azalttığını kanıtlamışlardır.

\section{Analiz Sonuçları}

Değişkenler arasında eşbütünleşme ilişkisinin olup olmadığını analiz etmeden önce, serilere birim kök testi uygulanmalıdır. Nitekim serilerde birim kökün varlı̆̆ı uzun dönemde iki değişken arasında eşbütünleşme ilişkisinin olabileceğine işaret etmektedir. Bu nedenle öncelikle değişkenlere Ziwot ve Andrews (1992) tek kırılmalı birim kök testi uygulanmıştır.

\section{Tablo 2. rgelir ve rharc Değişkenleri İçin Birim Kök Test Sonuçları}

\begin{tabular}{|c|c|c|c|c|}
\hline & rgelir & Kırılma Tarihleri & rharc & Kırılma Tarihleri \\
\hline Sabitli model & $-2.294(7)$ & $2016 C ̧ 2$ & $-3.140(4)$ & $2016 C ̧ 2$ \\
\hline $\begin{array}{c}\text { Sabitli ve Trendli } \\
\text { model }\end{array}$ & $-3.523(7)$ & $2016 C ̧ 4$ & $-3.763(4)$ & $2014 C ̧ 1$ \\
\hline$\Delta$ Sabitli model & $-21.765^{\mathrm{a}}(6)$ & $2013 C ̧ 3$ & $-5.017^{\mathrm{b}}(3)$ & $2015 \zeta ̧ 4$ \\
\hline $\begin{array}{c}\Delta \text { Sabit ve Trendli } \\
\text { model }\end{array}$ & $-12.320^{\mathrm{a}}(2)$ & $2002 \mathrm{C}_{3}$ & $-12.079^{\mathrm{a}}(3)$ & 2009 Ç4 \\
\hline
\end{tabular}

Sabitli model için tablo kritik değerleri 1\%, 5\%, 10\% için sırasıyla; -5.340, -4.800, -4.580, sabitli ve trendli model için ise $-5.570,-5.080,-4.820$ 'dir. Test istatistiklerinin hesaplanmasında Schwarz bilgi kriteri kullanılmış, varyans metodu olarak ise Bartlett-Kernel tercih edilmiştir. Parantez içindeki değerler gecikme uzunluklarını göstermektedir. a , b, sırasıyla \%1 ve \%5 seviyesindeki anlamlılık seviyelerini ifade etmektedir. 
Tablo 2'den görüleceği üzere rgelir ve $\operatorname{rharc}$ değişkenlerinin düzey değerleri için birim kök testi gerçekleştirildiğinde, hem sabitli hem de sabitli ve trendli modellerde $\% 1, \% 5$ ve $\% 10$ seviyelerinde değişkenlerin birim kök içerdiği; söz konusu iki değişkenin birinci farklarında durağan hale geldiği sonucuna ulaşılmıştır. Dikkat edilmesi gereken bir başka önemli husus rgelir ve rharc değişkenlerinde yapısal kırılmaların ne zaman meydana geldiğidir. rgelir değişkeni için sabitli modelde yapısal kırılmanın önemli siyasi ve ekonomik olayların yaşanmaya başladığı 2013: Ç3’te, sabitli ve trendli modelde yapısal kırılmanın ise Türkiye'de kriz sonrası dönem olan 2002: Ç3’te gerçekleştiği görülmektedir. rharc değişkeni için sabitli modelde yapısal kırılmanın 2015: Ç4’te, sabitli ve trendli modelde ise 2009: Ç4'te gerçekleştiği analiz sonuçlarından anlaşılmaktadır. Dolayısıyla iki değişken arasında eşbütünleşme ilişkisinin olup olmadığı araştırılabilinir. Bu amaçla uygulanan Gregory ve Hansen (1996) tek yapısal kırılmalı eşbütünleşme testi sonuçları Tablo 3'te verilmektedir.

Tablo 3. Gregory ve Hansen (1996) Tek Yapısal Kırılmalı Eşbütünleşme Testi Sonuçları

\begin{tabular}{|c|c|c|c|}
\hline Modeller & \multicolumn{2}{|c|}{ Test istatistikleri } & Kurılma Tarihleri \\
\hline \multirow{3}{*}{ Model C } & $A D F^{*}$ & $-6.829^{\mathrm{a}}$ & $2004 C ̧ 3$ \\
\cline { 2 - 4 } & $Z_{t}^{*}$ & $-6.837^{\mathrm{a}}$ & $2004 C ̧ 3$ \\
\cline { 2 - 4 } & $Z_{\alpha}^{*}$ & $-58.353^{\mathrm{a}}$ & $2004 C ̧ 3$ \\
\hline
\end{tabular}

\begin{tabular}{|c|c|c|c|}
\hline \multirow{3}{*}{ Model C/T } & $A D F^{*}$ & $-10.336^{\mathrm{a}}$ & $2004 C ̧ 1$ \\
\cline { 2 - 4 } & $Z_{t}^{*}$ & $-7.828^{\mathrm{a}}$ & $2008 C ̧ 3$ \\
\cline { 2 - 4 } & $Z_{\alpha}^{*}$ & $-58.353^{\mathrm{a}}$ & $2008 C ̧ 3$ \\
\hline
\end{tabular}

\begin{tabular}{|c|c|c|c|}
\hline \multirow{3}{*}{ Model C/S } & $A D F^{*}$ & $-7.075^{\mathrm{a}}$ & $2004 C ̧ 3$ \\
\cline { 2 - 4 } & $Z_{t}^{*}$ & $-7.070^{\mathrm{a}}$ & $2004 C ̧ 3$ \\
\cline { 2 - 4 } & $Z_{\alpha}^{*}$ & $-61.220^{\mathrm{a}}$ & $2003 C ̧ 1$ \\
\hline
\end{tabular}

Not: Model C, Model C/T ve Model C/S için $A D F^{*}$ ve $Z_{t}^{*}$ tablo kritik değerleri $\% 1, \% 5$ ve $\% 10$ için sırasıyla: $-5.130, \quad-4.610$, $-4.340, Z_{\alpha}^{*}$ için tablo kritik değerleri ise $\% 1, \% 5$ ve $\% 10$ için sırasılya: $-57.280,-47.960,-43.220$ 'dir. ${ }^{a} \% 1$ seviyesindeki anlamlllık seviyesini ifade etmektedir.

Gregory ve Hansen (1996) eşbütünleşme sonuçlarına göre Model C, Model C/T ve Model C/S için hesaplanan $A D F^{*}, Z_{t}^{*}, Z_{\alpha}^{*}$ test istatistik değerleri \%1 seviyesindeki tablo kritik değerinden büyük olduğu için eşbütünleşmenin olmadığını ifade eden sıfır hipotezi reddedilmektedir. Böylece değişkenler arasında \%1 seviyesinde bir yapısal kırılmayla birlikte eşbütünleşme ilişkisinin olduğu sonucuna ulaşılmaktadır. Sonraki aşamada ise Quintos (1995)'in öne sürdüğü şekilde eşitlik (4), Model C/T temel alınıp FMOLS, CCR, DOLS ve IM-OLS yöntemleriyle test edilerek $b$ katsayısı tahmin edilmiş ve bütçe açıklarının sürdürülebilirlik derecesinin ne olduğu sonucuna ulaşılmıştır. Bu modele göre test edilen uzun dönem eşbütünleşme katsayıları ise Tablo 4'te verilmiştir. 
Tablo 4. FMOLS, CCR, DOLS ve IM-OLS Uzun Dönemli Eşbütünleşme Katsayı Tahmin Sonuçları

\begin{tabular}{|c|cc|}
\hline Modeller & \multicolumn{2}{|c|}{ Katsayilar } \\
\hline \multirow{4}{*}{ FMOLS } & $\boldsymbol{b}$ & $\mathbf{0 . 4 4 3}^{\mathrm{a}}[\mathbf{9 . 6 6 1}]$ \\
& $\beta_{1}$ & $0.001[0.434]$ \\
& $\beta_{3}$ & $0.002^{\mathrm{a}}[12.722]$ \\
& $\beta_{4}$ & $-0.017^{\mathrm{a}}[-3.716]$ \\
\hline
\end{tabular}

\begin{tabular}{|l|cc|}
\hline \multirow{4}{*}{ CCR } & $\boldsymbol{b}$ & $\mathbf{0 . 4 4 0}[7.165]$ \\
& $\beta_{1}$ & $0.003[0.857]$ \\
& $\beta_{3}$ & $0.002^{\mathrm{a}}[10.110]$ \\
& $\beta_{4}$ & $-0.017^{\mathrm{a}}[-3.488]$ \\
\hline
\end{tabular}

\begin{tabular}{|l|cc|}
\hline \multirow{4}{*}{ DOLS } & $\boldsymbol{b}$ & $\mathbf{0 . 4 3 7 ^ { \mathrm { a } } [ \mathbf { 5 . 6 4 1 } ]}$ \\
& $\beta_{1}$ & $0.004[0.761]$ \\
& $\beta_{3}$ & $0.002^{\mathrm{a}}[8.117]$ \\
& $\beta_{4}$ & $-0.016^{\mathrm{a}}[-2.889]$ \\
\hline
\end{tabular}

\begin{tabular}{|c|c|c|}
\hline \multirow{4}{*}{ IM-OLS } & $\boldsymbol{b}$ & $0.409^{\mathrm{a}}[5.0054]$ \\
\hline & $\beta_{1}$ & $0.007[1.575]$ \\
\hline & $\beta_{3}$ & $0.002^{\mathrm{a}}[7.874]$ \\
\hline & $\beta_{4}$ & $-0.013^{\mathrm{a}}[-2.633]$ \\
\hline
\end{tabular}

anlamlılık seviyesini ifade etmektedir. [...] t istatistik değerlerini göstermektedir.

Tablo 4'te yer alan $b$ katsayısı tahmin sonuçlarına göre ele alınan 2000: Ç1-2018: Ç4 döneminde Türkiye'de bütçe açıklarının sürdürülebilirliğinin zayıf formda olduğu sonucuna ulaşılmaktadır. Buna göre Türkiye'de mevcut olarak uygulanan politikaların gözden geçirilmesi gerekmektedir. Aksi taktirde ısrar edilen açık yönlü bütçe politikalarının ve uygulanan maliye politikalarının ekonomik açıdan ciddi sorunlar yaratabileceği söylenebilir.

\section{Sonuç}

Bu çalışmada Türkiye'de mevcut bütçe politikalarının sürdürülebilirliği zamanlararası bütçe kısıtı yaklaşımıyla incelenmiştir. Çalışmanın temel çıkış noktası son yıllarda uygulanan mevcut bütçe politikalarının uzun vadede devam edip ettirilemeyeceği sorusudur. Bu amaçla bütçe açığının sürdürülebilirlik koşulu Quintos (1995)'in öne sürdürdüğü sürdürülebilirlik kriterleri esas alınarak analiz edilmiştir. Analizde merkezi yönetim reel gelirleri/GSYH ve merkezi yönetim reel harcamaları/GSYH değişkenleri kullanılmıştır. Teori gereğince bu değişkenler arasında önce eşbütünleşme ilişkisinin varlığı Gregory ve Hansen (1996) yapısal kırılmalı eşbütünleşme yöntemiyle analiz edilmiştir. İki değişken arasında eşbütünleşme ilişkisinin varlığının bulunmasıyla uzun dönem eşbütünleşme katsayısı FMOLS, CCR, DOLS ve IM-OLS yöntemleriyle tahmin edilmiştir. Bulunan katsayı Türkiye'de 2000: Ç1-2018: Ç4 arasında bütçe açıklarının zayıf sürdürülebilir olduğuna işaret etmektedir. Dolayısıyla mevcut bütçe politikalarının gözden geçirilmesi bir politika zorunluluğu olarak ortaya çıkmaktadır. Nitekim 
açık yönlü bütçe politikalarının devam etmesi orta ve uzun vadede ciddi makroekonomik sonuçları ortaya çıarabilecektir. Nitekim Quintos (1995)'te belirtildiği üzere zayıf sürdürülebilirlik durumunda mevcut politikalarda değişikliğe gidilmemesi uzun vadede kamunun borç bulmasında zorluk yaşamasına neden olacaktır.

Burada dikkat edilmesi gereken bir başka husus harcama ve gelir politikalarıly ilgilidir. Nitekim kamu harcamalarının ve gelirlerindeki oynaklığın artması uygulanacak politikaların etkinliğini azaltabilecek ve bu politikalara olan güveni sarsabilecektir. Çünkü maliye politikalarındaki sürekli değişiklik belirsizliğe neden olacaktır. Dolayısıyla maliye politikalarındaki sapmaların önüne geçilmesi gerekmektedir. Bu durumun önüne geçilebilmesi için Debrun vd. (2008) dört temel çözüm öne sürmüşlerdir. Bunlar; maliye politikasında karar alıcıların politikalarından dolayı hesap verebilir olması, maliye politikası kararların alınmasında olabildiğince politik baskılardan uzaklaşılması, bütçe süreçlerinin (hazırlık, onay ve uygulama) geliştirilmesi ve mali kuralların uygulamaya konulması. Dolayısıyla kamu maliyesi disiplininin sağlanmasına yönelik anlayış temel alınıp, uygulanan politikaların etraflıca düşünülmesi ve yeni bir anlayışın gündeme getirilmesi sürdürülebilirlik açısından önemli bir adım olacaktır.

\section{Kaynakça}

Adom, P. K., Amakye, K., Barnor, C., \& Quartey, G. (2015). The Long-Run Impact of Idiosyncratic And Common Shocks on Industry Output in Ghana. OPEC Energy Review, 39(March), 17-52.

Akkuş, Ö., Durmaz, A. (2019). Türkiye'de Bütçe Açı̆̆ının Sürdürülebilirliği: Saklı Eşbütünleşme İlişkisi. Maliye Dergisi, Ocak-Haziran(179), 52-71.

Altun, N. (2017). Türkiye'de Bütçe Açıklarının Sürdürülebilirliğinin Ampirik Olarak Analizi: 1950-2015 Dönemi. Ekonomik Ve Sosyal Araştırmalar Dergisi, 13(1), 13-22.

Aschersleben, P.; Wagner, M. (2016). Cointreg: Parameter Estimation And Inference in A Cointegrating Regression. $R$ Package Version 3.6.1. https://cran.rproject.org/web/packages/cointReg/index.html

Ataç, B. (2013). Maliye Politikası (10. Ed.). Ankara: Turhan Kitabevi.

Debrun, X., Moulin, L., Turrini, A., Ayuso-i-Casals, J.; S.Kumar, M. (2008). Tied to The Mast? National Fiscal Rules in The European Union. Economic Policy, (April), 297-362.

Egeli, H., Özen, A. (2017). Teori ve Uygulamada Bütçe Politikası (3. Ed.). İzmir: Kitapana.

Göktaş, Ö. (2008). Türkiye Ekonomisinde Bütçe Açı̆̆ının Sürdürülebilirliğinin Analizi. Ekonometri ve İstatistik Dergisi, 8, 45-64.

Gregory, Allan W., Hansen, B. E. (1996). Residual-Based Tests For Cointegration in Models With Regime Shifts. Journal of Econometrics, 70, 99-126. 
Hakkio, Craig S., Rush, M. (1986). Co-integration and the Government's Budget Deficit. Research Working Paper 86-12, Federal Reserve Bank Of Kansas City.

Hakkio, Craig S., Rush, M. (1991). Is The Budget Deficit “Too Large?” Economic Inquiry, 29(3), 429-445.

Hamilton, James D., Flavin, M. A. (1986). On The Limitations of Government Borrowing : A Framework For Empirical Testing. The American Economic Review, 76(4), 808-819.

Han, H.-L. (1996). Small Sample Properties of Canonical Cointegrating Regressions. Empirical Economics, 21, 235-253.

Kırca, M., Topal, M. H. (2017). Türkiye'de Turizm Talebinin Vergi Gelirleri Üzerindeki Etkisinin Analizi. Balkan Ve Yakın Doğu Sosyal Bilimler Dergisi, 03(02), 96-108.

Kuştepeli, Y., Önel, G. (2005). Fiscal Deficit Sustainability With A Structural Break: An Application to Turkey. Review Of Social, Economic \& Business Studies, 5(6), 189-208.

Mensah, J. T. (2014). Carbon Emissions, Energy Consumption And Output: A Threshold Analysis On The Causal Dynamics in Emerging African Economies. Energy Policy, 70, $172-182$.

Özatay, F. (1997). Sustainability of Fiscal Deficits, Monetary Policy, and Inflation Stabilization: The Case Of Turkey. Journal of Policy Modeling, 19(6), 661-681.

Özcan, S. E. (2011). Statik Mali Sürdürülebilirlik Analizleri. Maliye Dergisi, 160, 228-241.

Park, J. Y. (1992). Canonical Cointegrating Regressions. Econometrica, 60(1), 119-143.

Payne, J. E., Mohammadi, H., Cak, M. (2008). Turkish Budget Deficit Sustainability and The Revenue-Expenditure Nexus. Applied Economics, 40(7), 823-830.

Phillips, Peter C. B., Hansen, B. E. (1990). Statistical Inference in Instrumental Variables Regression With (1) Processes. The Review of Economic Studies, 57(1), 99-125.

Pressman, S. (2006). The Role of The State and The State Budget. Richard P.F. Holt ve Steven Pressman (Ed), A New Guide to Post Keynesian Economics İçinde (S. 102-113). Routledge.

Quintos, C. E. (1995). Sustainability of The Deficit Process with Structural Shifts. Journal of Business and Economic Statistics, 13(4), 409-417.

Şen, H., Sağbaş, İ., Keskin. A. (2007). Bütçe Açıkları ve Açık Finansman Politikası Teori ve Türkiye Uygulaması (2. Ed.). Ankara: Orion.

Şen, H., Sağbaş, İ., Keskin, A. (2010). Türkiye’de Mali Sürdürülebilirliğin Analizi: 1975-2007. Maliye Dergisi, Ocak-Haziran(158), 103-123.

Stock, J. H., Watson, M. W. (1993). A Simple Estimator of Cointegrating Vectors in Higher Order Integrated Systems. Econometrica, 61(4), 783.

Trehan, B., Walsh, C. E. (1988). Common Trends, The Government's Budget Constraint, and Revenue Smoothing. Journal Of Economic Dynamics And Control, 12, 425-444. 
Trehan, B., Walsh, C. E. (1991). Testing Intertemporal Budget Constraints: Theory And Applications to U.S. Federal Budget And Current Account Deficits. Journal Of Money, Credit And Banking, 23(2), 206-223.

Ulusoy, Ahmet; Karakurt, Birol; Ela, M. (2015). Borç Deflasyonu: Teorinin Gelişimi ve Avrupa'da Borç Deflasyonuna İlişkin Değerlendirmeler. Uluslarararası Yönetim İktisat Ve İsletme Dergisi, 11(26), 1-28.

Vogelsang, T. J., Wagner, M. (2014). Integrated Modified OLS Estimation And Fixed-b Inference For Cointegrating Regressions. Journal Of Econometrics, 178(2), 741-760.

Wilcox, D. W. (1989). The Sustainability of Government Deficits : Implications of The PresentValue Borrowing Constraint. Journal of Money, Credit And Banking, 21(3), 291-306.

Yılancı, V., Özcan, B. (2010). Yapısal Kırılmalar Altında Türkiye İçin Savunma Harcamaları İle GSMH Arasındaki İlişkinin Analizi. C.Ü. İktisadi Ve İdari Bilimler Dergisi, 11(1), 21-33. 